\title{
Effects of Blast Furnace Slag with Iron Ore Containing Rare Earth Elements on Combustion Characteristics of Pulverized Coal
}

\author{
Qi-Wei Zuo ${ }^{* 1,2}$, Da-Qiang Cang ${ }^{1,2}$ and Xia $\mathrm{An}^{3}$ \\ ${ }^{I}$ School of Metallurgical and Ecological Engineering, University of Science \&Technology Beijing, China \\ ${ }^{2}$ State Key Laboratory of Advanced Metallurgy, Beijing, China \\ ${ }^{3}$ Tangshan Iron and Steel Co., Ltd. Tangshan, China
}

\begin{abstract}
The combustion characteristics of pulverized coal when using blast furnace slag charged with iron ore containing rare earth elements as a composite catalyst were investigated by thermo gravimetric analysis. The results show that the combustion char acteristics of pulverized coal loaded with $21.3 \%$ by weight of blast furnace slag containing $15 \%$ rare earth ore are better than those of others. It is also indicated that the composite catalyst promotes combustion of volatiles and also performs well for carbon residue. The mechanism of promotion by the composite catalyst was explored. The kinetic parameters calculated by the Coats-Redfern model show that the activation energy(E) was reduced by 10 $\mathrm{kJ} / \mathrm{mol}$, the time of combustion was shortened by $3 \mathrm{~min}$, pre-exponential factor(A) reached $2.7 \times 10^{4} / \mathrm{min}$ and general combustion characteristic index (S )was 1.09.
\end{abstract}

Keywords: Pulverized coal (PC), catalyst, thermo gravimetric analysis, rare earth ore, blast furnace slag, kinetic model.

\section{INTRODUCTION}

Studies have been conducted to improve the characteristics of pulverized coal (PC) to shorten combustion time during its passage through the raceway, increase coke ration, and reduce costs. Previous reports show that adding a catalyst provides an efficient mechanism for combustion [1]. Alkali, alkaline-earth metal, transition metal, and rare-earth compounds have been widely used as catalysts [2-5]. Alkali compounds are hazardous, while transition metal compounds exhibit beneficial effects [6]. Shen and co-workers [7] found that oxygen decomposition of $\mathrm{MnO}_{2}$ accelerates burning activation energy and pre-exponential factor at different catalyst loading are discussed. The mechanism has also been tentatively explored.

\section{MATERIAL AND METHODS}

\subsection{Experimental Materials}

The results of ultimate and proximate analysis of PC are shown in Table $\mathbf{1 .}$

Table 1. Ultimate, proximate analysis and calorific value of coal sample.

\begin{tabular}{|c|c|c|c|c|c|c|c|c|c|}
\hline \multirow{2}{*}{ Grade } & \multicolumn{7}{|c|}{ Percentage } & \multirow{2}{*}{ Constant Volume Heating Value (J/g) } \\
\cline { 2 - 10 } & $\mathbf{F C}_{\text {ad }}$ & $\mathbf{A}_{\text {ad }}$ & $\mathbf{V}_{\text {ad }}$ & $\mathbf{C}_{\text {ad }}$ & $\mathbf{H}_{\text {ad }}$ & $\mathbf{O}_{\text {ad }}$ & $\mathbf{N}_{\text {ad }}$ & $\mathbf{S}_{\text {ad }}$ & \\
\hline \hline $\mathrm{PC}$ & 68.76 & 8.07 & 23.38 & 75.66 & 3.91 & 10.64 & 0.75 & 0.27 & 28667.72 \\
\hline
\end{tabular}

Note: FCad, Vad, and Aad were based on air-dried samples.

speeds in Northeastern University. ZHANG and co-workers [8] found that $\mathrm{CeO}_{2}$ improves the combustion of carbon in University of Science \&Technology Beijing.

The combustion of PC can be divided into three stages displaying different mechanisms. Many disadvantages for single catalysts have been discovered. Herein, the combustion characteristics of PC and parameters such as the

*Address correspondence to this author at the School of Metallurgical and Ecological Engineering, University of Science \&Technology Beijing, China; Tel: 15101033529; E-mail: zuoqiwei8618@163.com
The composition of blast furnace (BF) slag is shown in Table 2.

Table 2. Composition of BF slag.

\begin{tabular}{|c|c|c|c|c|}
\hline \multicolumn{5}{|c|}{ Percentage } \\
\hline $\mathbf{C a O}$ & $\mathbf{M g O}$ & $\mathbf{S i O}_{2}$ & $\mathbf{A l}_{\mathbf{2}} \mathbf{O}_{3}$ & Remain \\
\hline \hline 41.66 & 15.3 & 28.18 & 11.54 & 3.32 \\
\hline
\end{tabular}

Note: FCad, Vad, and Aad were based on air-dried samples. 
The percentage of elements of iron ore containing rear earth elements is shown in Table $\mathbf{3}$.

Table 3. Percentage of elements in ore.

\begin{tabular}{|c|c|c|c|c|c|}
\hline \multicolumn{7}{|c|}{ Percentage } \\
\hline Fe & Ca & F & La & Y & Remain \\
\hline \hline 32.03 & 14.21 & 12.08 & 1.34 & 0.03 & 40.31 \\
\hline
\end{tabular}

The slag is taken from Baogang group which locates in Inner Mongolia Autonomous Region.

\subsection{Experimental Design}

An HCT-3 differential thermo analysis apparatus was manufactured by Beijing Hengjiu. The system includes a balance, a control system for temperature and atmosphere, and a computer.

The $\mathrm{PC}$ was dried at $105^{\circ} \mathrm{C}$ for $2 \mathrm{~h}$. The ration $\mathrm{BF}$ slag to iron ore containing rare-earth elements was kept constant at $17: 3$. The weight of coal was $14.5 \pm 0.1 \mathrm{mg}$, and the volume of the Al2O3crucible was $0.06 \mathrm{ml}$. Air was flowed at 100 $\mathrm{ml} / \mathrm{min}$, and the temperature increased at the rate of $10^{\circ} \mathrm{C}$ $/ \mathrm{min}$ from room temperature. The thermo gravimetric (TG) and differential thermo gravimetric (DTG) curves were recorded automatically by using the attached computer. The variations in experiments are shown in Table 4.

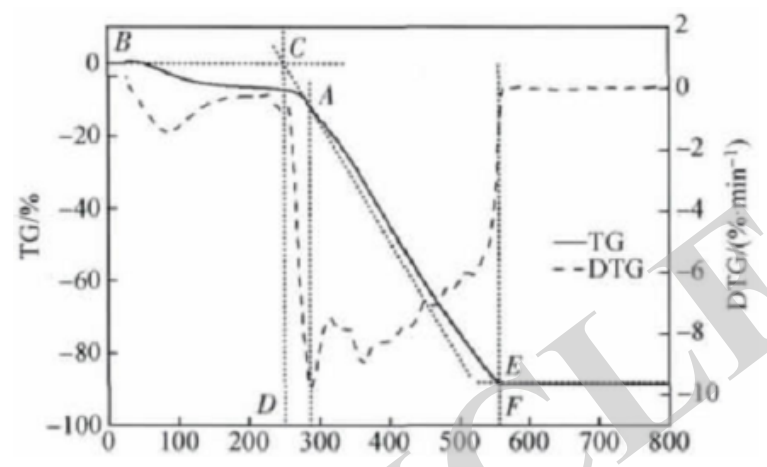

Fig. (1). Determination of ignition temperature.

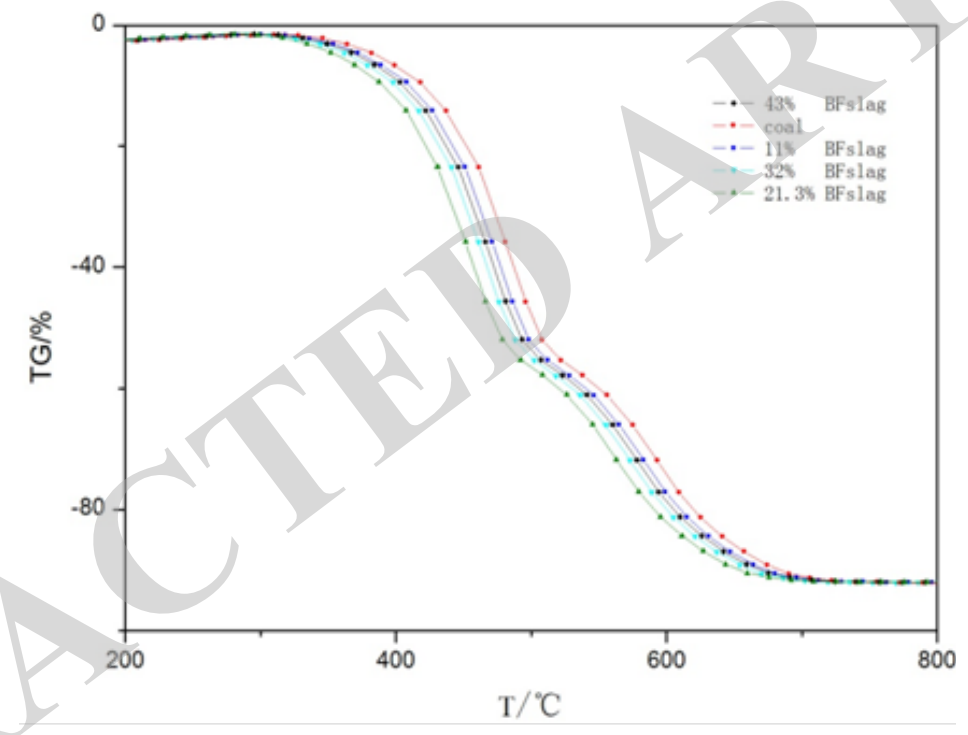

Fig. (2). TG curves of samples.

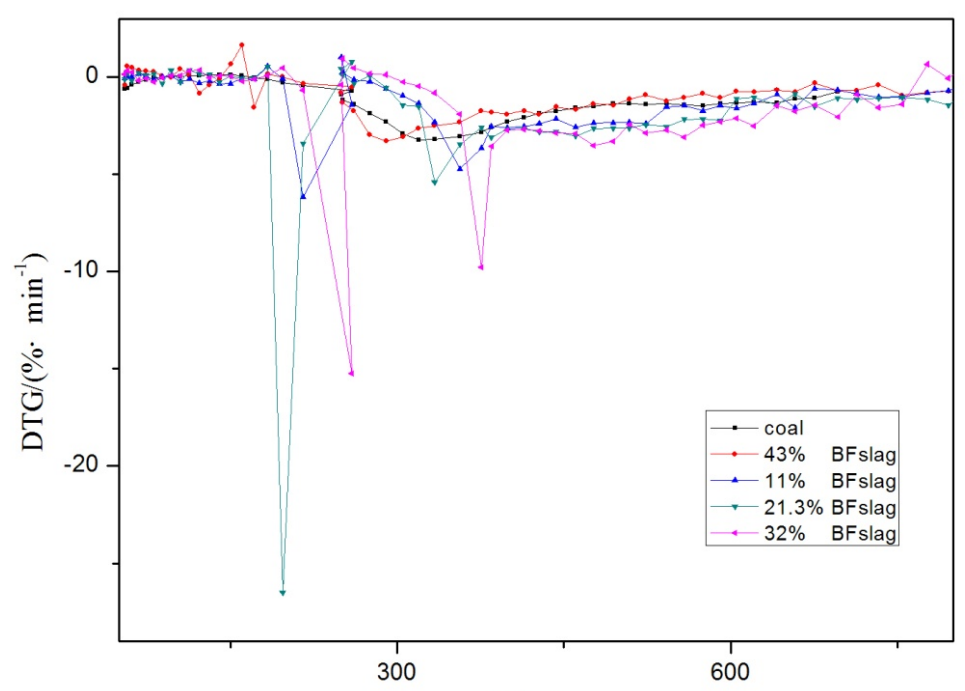

Fig. (3). DTG curves of samples. 
Table 4. Experimental variations.

\begin{tabular}{|c|c|c|}
\hline NO. & Catalyst & Percentage \\
\hline \hline 1 & 0 & 0 \\
\hline 2 & \multirow{3}{*}{ BF slag } & 11 \\
\cline { 1 - 1 } & & 21.3 \\
\hline 4 & & 32 \\
\hline \multirow{2}{*}{5} & & 43 \\
\hline
\end{tabular}

\subsection{Evaluating the Indicator of Combustion}

The general combustion characteristic index S [9] was used as an indicator of combustion, where a larger value indicates better combustion. $\mathrm{S}$ can be expressed by the following equation (1):

$$
S=\frac{(d w / d t)_{\max }(d w / d t)_{\text {mean }}}{T_{I}^{2} T_{F}}
$$

where, $(\mathrm{dw} / \mathrm{dt})_{\max }$ is the maximum combustion rate, $(\% / \mathrm{min})$; $(\mathrm{dw} / \mathrm{dt})_{\text {mean }}$ is the average combustion rate, $(\% / \mathrm{min}) ; \mathrm{T}_{\mathrm{I}}$ is the ignition temperature, $\mathrm{K}$, and $\mathrm{T}_{\mathrm{F}}$ is the burn-off temperature, $\mathrm{K}$.

The method [4] used for determining the ignition temperature is shown in Fig. (1).

A perpendicular line drawn from the peak of the DTG curve intersects the TG curve at point $\mathrm{A}$. The tangent line from point $A$ intersects horizontally at point $C$. The temperature at point $\mathrm{C}$ was taken as the ignition temperature. The temperature at which the sample lost $98 \%$ of the total weight was taken as the burn-off temperature (E). The time was also determined.

\section{RESULTS AND ANALYSIS}

\subsection{TG and DTG}

The effects of the catalyst on the combustion characteristics at different content ratios are shown in Figs. $(\mathbf{2}, \mathbf{3})$.

The TG curve shows that an increase in catalyst content improves the combustion characteristics of PC. The ignition temperature decreases and the rate of combustion increases. The most effective combustion was achieved when the content of the catalyst was $21.3 \mathrm{wt} \%$.

The momentary weight loss rate is shown by the DTG curve. The shape of the curve gets sharper and reaches a peak at a content of $21.3 \mathrm{wt} \%$. The position of the peak shifts in relation to the type and content of catalyst.

\subsection{Effects of Catalyst on Combustion Parameters}

The combustion parameters of PC are shown in Table 5.

$\mathrm{T}_{\mathrm{I}}$, ignition temperature, $\mathrm{K} ; \mathrm{T}_{1}$, peak temperature, $\mathrm{K} ; \mathrm{T}_{\mathrm{F}}$, burn-off temperature, $\mathrm{K}$.

PC combustion becomes more efficient with the inclusion of a catalyst, with the most effective being the third group shown in Table 5. $\mathrm{T}_{\mathrm{I}}$ decreases to $699.5 \mathrm{~K}, \mathrm{~T}_{1}$ decreases to $723.3 \mathrm{~K}$, and $\mathrm{T}_{\mathrm{F}}$ decreases to $880.5 \mathrm{~K}$. The maximum and average weight losses are $8.39 \% / \mathrm{min}$ and $5.61 \% / \mathrm{min}$, respectively. The process time was shortened by $3 \mathrm{~min}$ and the value of $\mathrm{S}$ was 1.09 .

A lower ignition temperature means the catalyst can cause the lixiviation of volatiles at an earlier stage. The

Table 5. Combustion parameters of $\mathrm{PC}$ with catalyst.

\begin{tabular}{|c|c|c|c|c|c|c|c|}
\hline Percentage & $\mathbf{T}_{\mathbf{I}} / \mathbf{K}$ & $\mathbf{T}_{\mathbf{1}} / \mathbf{K}$ & $(\mathbf{d w} / \mathbf{d t}) \mathbf{m a x} /\left(\mathbf{\%} \cdot \mathbf{m i n}^{-\mathbf{1}}\right)$ & $(\mathbf{d w} / \mathbf{d t}) \mathbf{m e a n} /\left(\mathbf{\%} \cdot \mathbf{m i n}^{-\mathbf{1}}\right)$ & $\mathbf{T}_{\mathbf{F}} / \mathbf{K}$ & $\mathbf{t} / \mathbf{m i n}$ & $\left.\mathbf{S} \times \mathbf{1 0} \mathbf{0}^{7} /\left(\mathbf{( \%} \cdot \mathbf{m i n}^{-1}\right)^{\mathbf{2}} \cdot \mathbf{K}^{-\mathbf{3}}\right)$ \\
\hline \hline 0 & 723.3 & 739.1 & 6.89 & 5.07 & 915.3 & 19.7 & 0.730 \\
\hline 11 & 709.6 & 737.2 & 6.99 & 5.41 & 890.6 & 18.1 & 0.843 \\
\hline 21.3 & 699.5 & 723.3 & 8.39 & 5.61 & 880.5 & 16.8 & 1.09 \\
\hline 32 & 707.8 & 741.5 & 7.59 & 5.52 & 895.3 & 17.8 & 0.934 \\
\hline 43 & 705.4 & 745.4 & 7.39 & 5.35 & 890.8 & 18.5 & 0.892 \\
\hline
\end{tabular}

Table 6. Parameters of combustion.

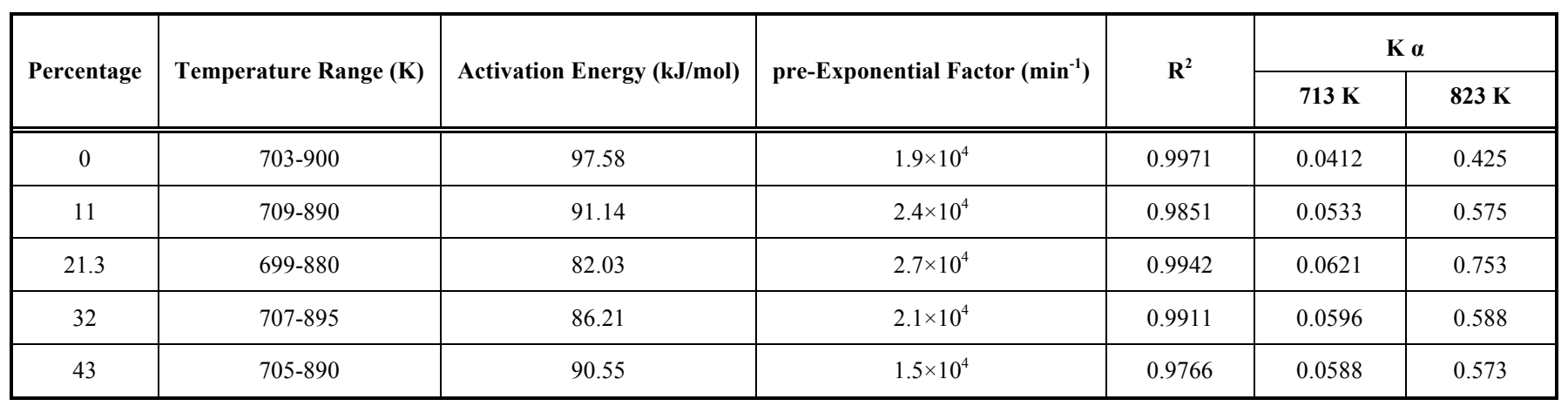


combustion of volatiles accelerates the process and increases the speed of the reaction.

The best combustion efficiency at $21.3 \%$ catalyst content indicates that only a small amount of the catalyst is required, beyond which the catalyst coats the PC particles and blocks the pathway of oxygen, which further reduces diffusion and limits the efficiency.

\subsection{Kinetic Analysis}

During the non-isothermal and heterogeneous process [1011], the linear equation of $\mathrm{d} \alpha / \mathrm{dt}$, reaction rate constant $\mathrm{k}$, and combustion function $\mathrm{f}(\alpha)$ can be expressed in the following way:

$\frac{d \alpha}{d t}=k f(\alpha)=A \exp \left(-\frac{E}{R T}\right) f(\alpha)$

where, $\alpha$ is the rate of conversion, $\mathrm{A}$ is the pre-exponential factor, and $\mathrm{E}$ is the activation energy.

$f(\alpha)$ is expressed in the following way:

$$
f(\alpha)=(1-\alpha)^{n}
$$

where, $\mathrm{n}$ is the order of reaction.

$\alpha$ is expressed in the following way:

$\alpha=\frac{m_{i}-m_{t}}{m_{i}-m_{\infty}}$ where, $m_{i}$ is the initial mass, $m_{t}$ : is the mass at time $t$, and $m_{\infty}$ is the final mass.

The heating rate $(\beta)$ is expressed in the following way:

$\beta=\frac{d T}{d t}$

Introducing equations (3) and (5) in (2) gives

$\frac{d \alpha}{(1-\alpha)^{n}}=\frac{A}{\beta} \exp \left(-\frac{E}{R T}\right) d T$

The order of PC combustion is 1. Taking the integral of (6)gives,

$\ln \left(-\frac{\ln (1-\alpha)}{T^{2}}\right)=\ln \left[\frac{A R}{\beta E}\left(1-\frac{2 R T}{E}\right)\right]-\frac{E}{R T}$

When $\frac{\mathrm{E}}{\mathrm{RT}} \geq 1$ and $\left(1-\frac{2 \mathrm{RT}}{\mathrm{E}}\right) \approx 1$ cause, $\ln \left[\frac{\mathrm{AR}}{\beta \mathrm{E}}(1-\right.$ $\left.\left.\frac{2 \mathrm{RT}}{\mathrm{E}}\right)\right]$ as is constant at normal temperature. The linear equation $\mathrm{y}=\mathrm{kx}+\mathrm{b}$ can be achieved through line-fitting. The activation energy( E ) and pre-exponential factor (A )were calculated by using the slope coefficient $k=-\frac{E}{R}$ and intercept $\mathrm{b}=\ln \frac{\mathrm{AR}}{\beta \mathrm{E}}$.

The fitting results in the different content of catalyst are shown in Figs. (3-8).

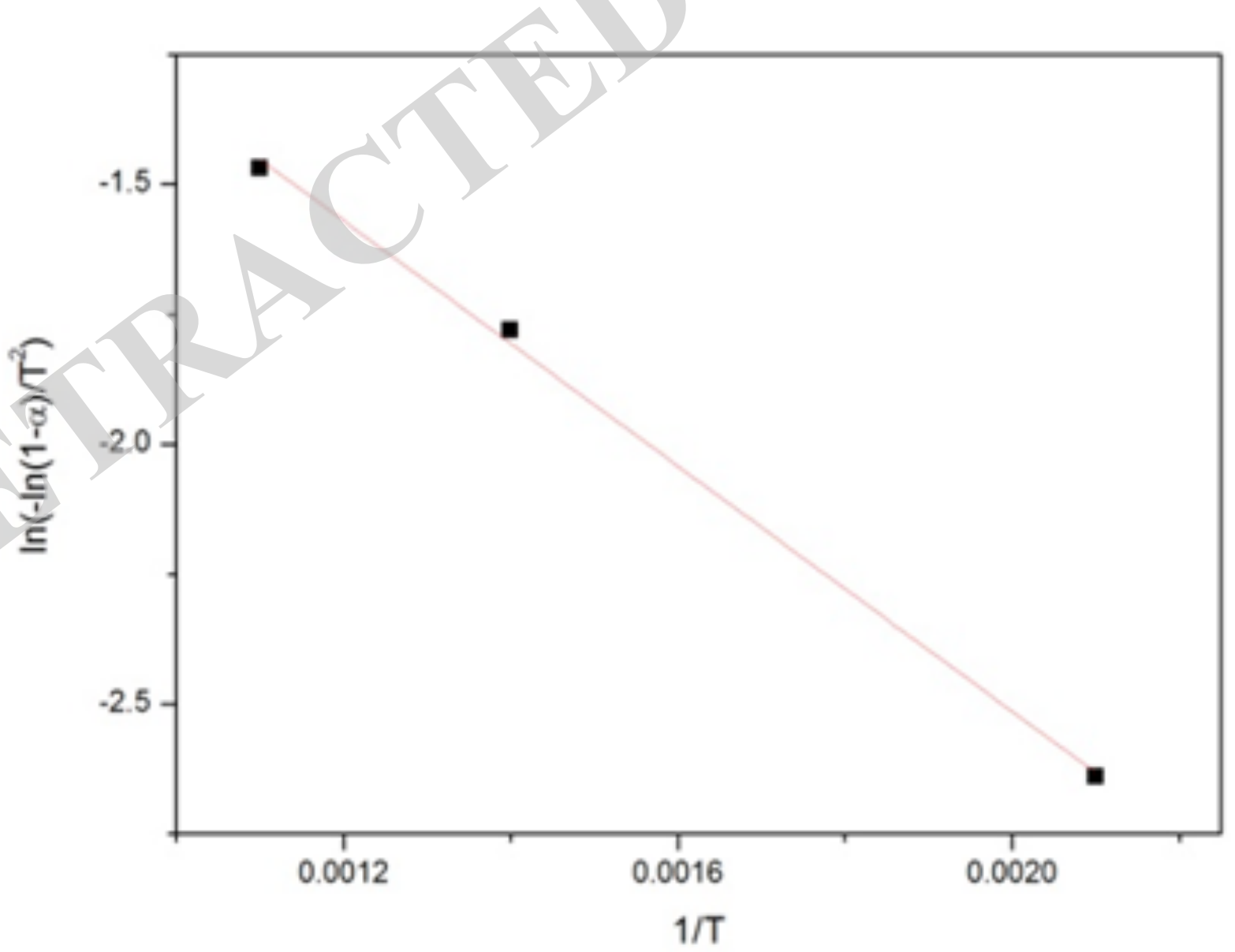

Fig. (4). The content of catalyst is 0 . 


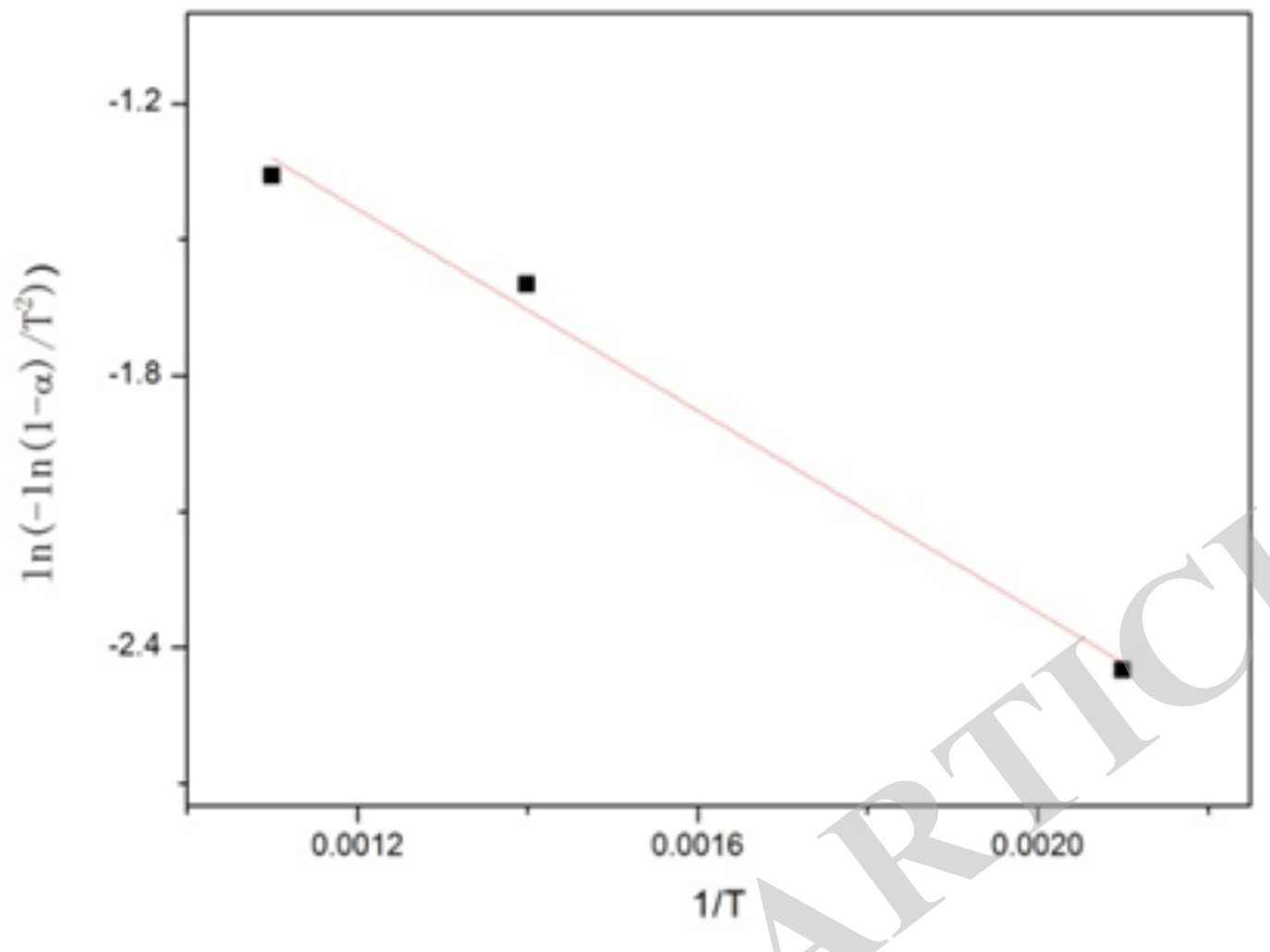

Fig. (5). The content of catalyst is $11 \%$.

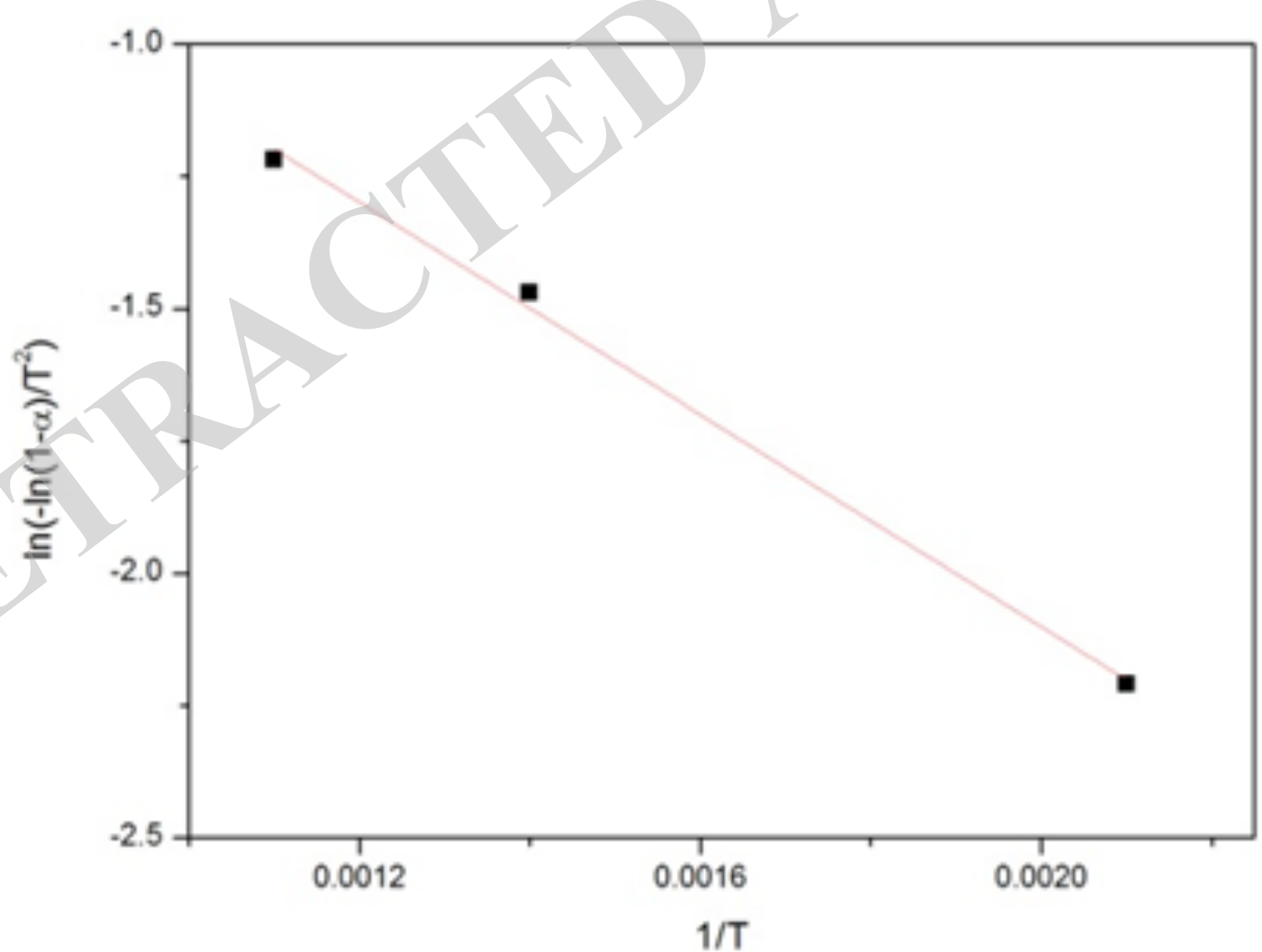

Fig. (6). The content of catalyst is $21.3 \%$. 


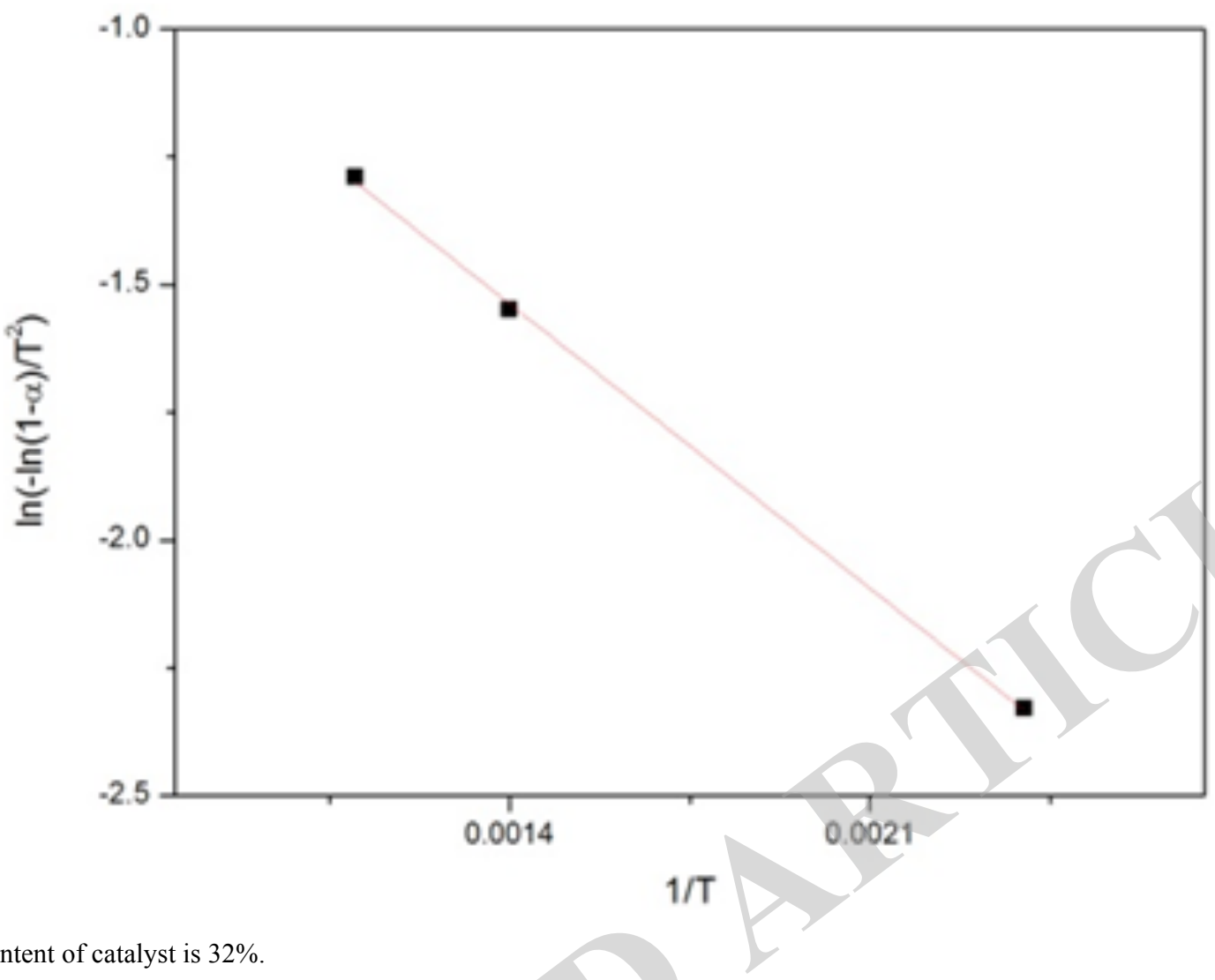

Fig. (7). The content of catalyst is $32 \%$.

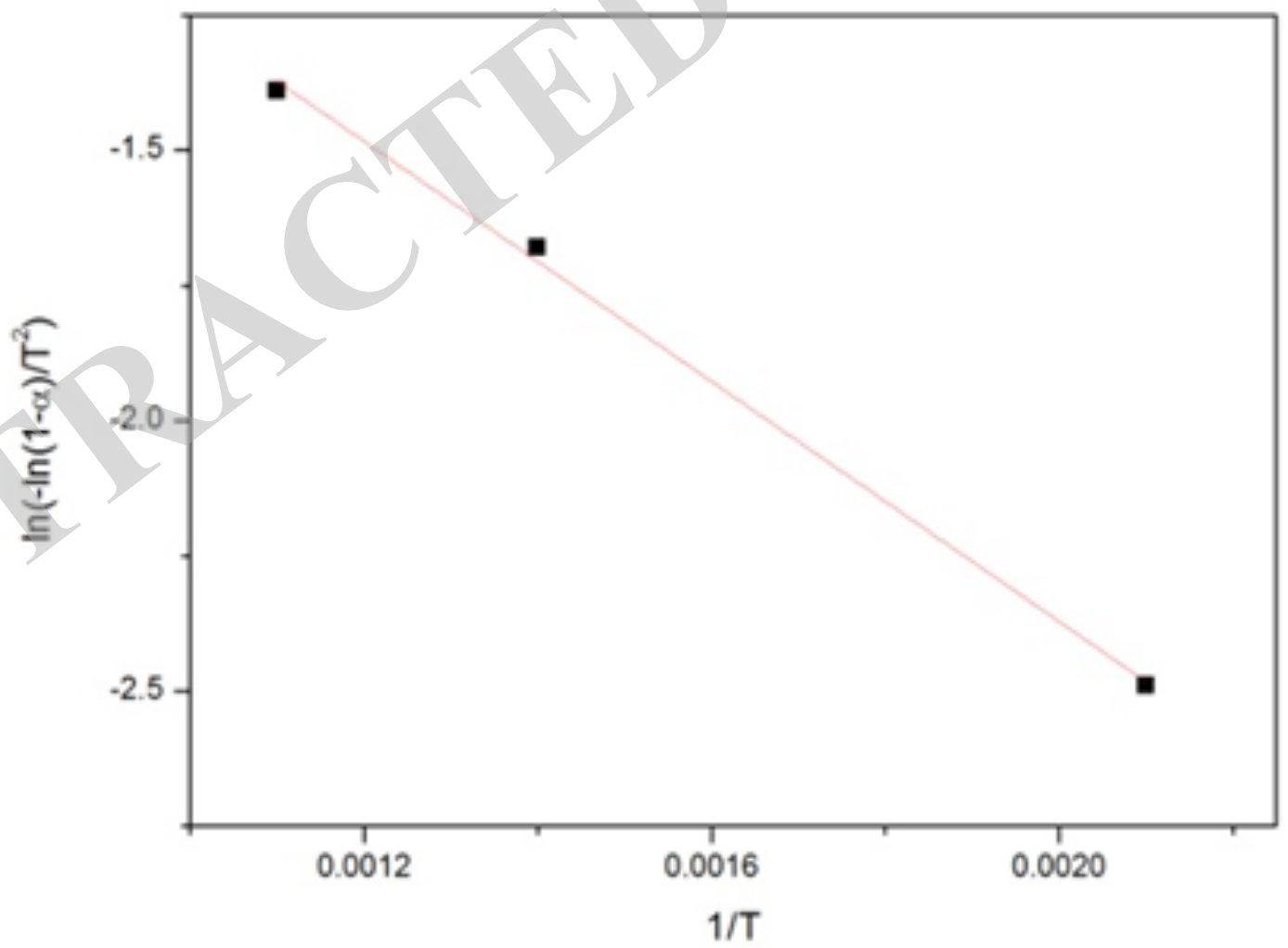

Fig. (8). The content of catalyst is $43 \%$. 
The kinetics parameters achieved by the method above are shown in Table 6.

The range of coefficients is $0.9766-0.9971$. What the range of coefficients shows a good correlation to the function.

When the ignition temperature decreases, the activation energy is reduced by $10 \mathrm{~kJ} / \mathrm{mol}$ and the time of combustion shortens by around $3 \mathrm{~min}$. The value of the pre-exponential factor ranged from $1.9 \times 10^{4}-2.7 \times 10^{4} / \mathrm{min}$. To check the effect of the catalyst under different temperatures, $\mathrm{K} \alpha$ was also calculated and the results are shown in Table $\mathbf{6}$.

$\mathrm{K}_{\alpha}$ can be defined as the following way,

$\mathrm{K}_{\alpha}=(-\mathrm{E} / \mathrm{RT})$. Where, R, gas constant, $8.314 \mathrm{~J} /(\mathrm{mol} \cdot \mathrm{K})$, other parameters as mentioned above.

The process of thermolytic dissociation can be divided into two parts dehydrogenation condensation and decarburization cracking.

Dehydrogenation condensation occurs when the hydrogen bond is broken so that the aromatic products such as benzene, ortho-xylene and paraffin can be condensed to form coke. Decarburization occurs when the covalent carbon bond is broken, and then the formation of active free radicals continues to split the coal into smaller gaseous molecules. Combustion occurs after contact with oxygen.

It is well known that compound catalysts provide better effects than single catalysts. BF slag with iron ore containing rare-earth elements can improve the combustion characteristics of PC.

Undersaturation improves the combustion properties by increasing the combustion rate in the presence of rare earth elements. The electronic shell structure produces the characters of a metastable state; vacancies and ions format the current rate, which can absorb $\mathrm{O}_{2}, \mathrm{O}^{2-}$, and $\mathrm{O}^{-}$to accelerate the process of combustion.

At the initial stage of combustion, the reduction environment reduces $\mathrm{Fe}_{2} \mathrm{O}_{3}$ to $\mathrm{FeO}$. The reverse reaction happens in the absence of the environment. With the help of $\mathrm{Fe}^{2+}$ and $\mathrm{Fe}^{3+}$, oxygen is transported through a series of reactions as follows.

$$
\left.\mathrm{C}+\mathrm{O} \rightleftarrows \mathrm{C}[\mathrm{O}] \rightleftarrows \mathrm{C}_{\mathrm{X}} \mathrm{O}_{\mathrm{Y}} ; \mathrm{C}_{\mathrm{X}} \mathrm{O}_{\mathrm{Y}} \rightleftarrows \mathrm{CO}+\mathrm{CO}_{2} ; \mathrm{CO}_{2} \rightleftarrows \mathrm{CO}\right)
$$

The results accelerate the process of combustion.

Another reason for improved combustion was attributed to lattice defects and vacancies in compounds which favor the inclusion of oxygen. Further studies need to be conducted to gain a deeper understanding.

\section{CONCLUSION}

1) According to the results of thermo gravimetric analysis, BF slag with iron ore containing rare earth elements as a composite catalyst improved combustion characteristics of PC, with the most efficient catalyst content being $21.3 \mathrm{wt} \%$.

2) The catalysts can improve the combustion of volatiles and carbon residue; however, the improvement was more prominent for the latter.

3) The regulation of combustion characteristics of PC with different contents was explored. Results of the kinetic analysis show that the best case was determined to have an activation energy and a preexponential factor of $82.03 \mathrm{~kJ} / \mathrm{mol}$ and $2.7 \times 10^{4} \mathrm{~min}^{-1}$, respectively.

\section{CONFLICT OF INTEREST}

The authors confirm that this article content has no conflict of interest.

\section{ACKNOWLEDGEMENTS}

This work is supported by the State Key Program of National Natural Science of China (Grant No.51034008).

\section{REFERENCES}

Babich, A.; Yaroshevskii, S.; Formoso, A. Increase of pulverized coal use efficiency in blast furnace. ISIJ International,1996, $36,(10), 1250-1258$.

[2] Li, H.; Lin, Q. Effect of alkali, alkaline-earth metal, transition metal on combustion of pulverized coal, Journal of Dalian University of Technology, 1989, 29, ,(3), 289.

[3] Xu, W.; Du, H. Characteristics of thermolytic dissociation of PC and effects of Catalyst, Iron and Steel, 1999,34, (6), 7.

[4] Gong, X.; Guo, Z. C.; Wang, Z. Effects of $\mathrm{K}_{2} \mathrm{CO}_{3}$ and $\mathrm{Fe}_{2} \mathrm{O}_{3}$ on combustion characteristics of pulverized coal by thermogravimetric analysis. Journal of Fuel Chemistry and Technology, 2009, 37, (1), 42.

[5] Wei, L.; Qi, D.; Li, R. Effects of alkali on combustion characteristics of pulverized coal and analysis of kinetics. Journal of China Coal Society, 2010, 35, (10), 1706.

[6] Liu, Y.; Che, D.; Li, Y. Effects of iron compounds on combustion characteristics of pulverized coal. Journal of Xi'an Jiaotong University, 2000, 34, (9), 20

[7] Shen, F.; Peng, X.; Zhao, Q.; Effects and mechanism of $\mathrm{MnO} 2$ on combustion characteristics of pulverized coal. Iron and Steel, 1998, 33, (9), 1.

[8] Zhang, J.; Tang, Y.; Wang, G. Effects of $\mathrm{CeO}_{2}$ and its compound on combustion efficacy of PC. Iron and Steel, 2013, 48, (9), 81. 
[9] Jiang, X.; J.; Qiu, J. Study on the combustion characteristics of ultrathin pulverized coal. Proceedings of the CSEE, 2000, 20, (6), 71.

[10] Zou, S. P.; Wu, Y. L.; Yang, M. D. Li, C.; Tong, J. Pyrolysis characteristics and kinetics of the marine microalgae Dunaliella tertiolecta using thermogravimetric analyzer. Bioresource Technology, 2010, 101, (1), 359-365.

[11] Boonchom, B.; Puttawong, S. Thermodynamics and kinetics of the dehydration reaction of FePO4•2H2O. Phys B, 2010, 405, (9), 2350 .

(C) Zuo et al.; Licensee Bentham Open.

This is an open access article licensed under the terms of the Creative Commons Attribution Non-Commercial License (http://creativecommons.org/licenses/ by-nc/3.0/) which permits unrestricted, non-commercial use, distribution and reproduction in any medium, provided the work is properly cited. 